\title{
Evaluating the Impact of Storytelling Ads on Consumer Purchase Intention
}

\author{
Sujata Joshi', Menachem Domb², Barshekee Chanda², Amit Bais ${ }^{2}$ \\ ${ }^{1}$ Symbiosis Institute of Digital and Telecom Management, Symbiosis International (Deemed University), Lavale, Pune, India \\ ${ }^{2}$ Computer Science, Ashkelon Academy, Ben Zvi, Ashkelon, Israel \\ Email: sjoshi@sidtm.edu.in,dombmnc@edu.aac.ac.il
}

How to cite this paper: Joshi, S., Domb, M., Chanda, B., \& Bais, A. (2022). Evaluating the Impact of Storytelling Ads on Consumer Purchase Intention. Journal of Service Science and Management, 15, 10-22. https://doi.org/10.4236/jssm.2022.151002

Received: November 16, 2021

Accepted: January 27, 2022

Published: January 30, 2022

Copyright (c) 2022 by author(s) and Scientific Research Publishing Inc. This work is licensed under the Creative Commons Attribution International License (CC BY 4.0).

http://creativecommons.org/licenses/by/4.0/ (c) (P) Open Access

\begin{abstract}
Marketing Analytics is gaining much importance in the current digital transformation age. Marketers consider and experiment with new-age marketing communication tactics to ensure their advertisements are engaging. Storytelling is one such form of advertising which is gaining momentum. This paper aims to evaluate the impact of Storytelling on consumer purchase intentions. We ran a survey of 150 participants who underwent advertisement viewing and later filled a questionnaire in this study. The collected data was analysed using marketing analytics and statistical tools such as Factor analysis and Regression analysis.
\end{abstract}

\section{Keywords}

Storytelling, Brand Association, Marketing Analytics, Quantitative Method, Brand Value, Consumer Purchase Intention

\section{Introduction}

Most companies have adopted marketing analytics to measure, manage, and analyze their performance to maximize their effectiveness and investment return. Sales and lead generation are part of analytics; it helps to decipher consumers' preference and trends. One robust market analysis uses the keywords of the most popular searches.

We have noticed that brands leverage the power of human connections using Storytelling for selling their brand. Storytelling is a concept taught to human beings and the reason why marketers are using it. Stories can be of different forms, educational, emotional, motivating, influential, or comic. It helps organizations create leads to connections to influence and gauge the crowd's attention. Nowadays, attention span has become shorter, requiring a solid and lasting im- 
pression (Decker, 2021).

Storytelling as a marketing communication has existed for a while. Advertisers are aware of its advantages in creating an emotional connection with consumers, building customer engagement, increasing brand recall value, etc.

The impact of Storytelling in advertising already appears in various contexts such as brand experiences (Lundqvist et al., 2013), Brand Image, perceived quality, and purchase intention (Pan \& Chen, 2019), Consumer response (Hong et al., 2018), Consumer Trust (Li, Zou, \& Yang, 2019), Behavioral Intention (Yang, 2018), Marketing (Yueh \& Zheng, 2019), Consumer attitude formation towards product and brands (Cheung \& Lau, 2012). However, very few studies have focused on its impact on consumer purchase intention. Hence the objective of this study is to find out the effect of Storytelling ads on purchase intention

\section{Literature Review}

\subsection{Purchase Intention}

The Business Dictionary defines Purchase Intention as "a plan to purchase a particular good or service in the future" (Bhasin, 2018). According to Shah et al. (2012), Purchase Intention is the customer's decision to buy some product or brand for a particular reason. Attitude reflects the consumer's feelings about the object, irrespective of how much they like it. It also instils confidence in the consumer in the various attributes and features the brand is trying to sell. Lars (2012) defines consumer attitude "as a composite of a consumer's beliefs, feelings, and behavioural intentions toward some object within the context of marketing."

In the persuasion process, the Theory of Reasoned Action, along-with attitude, adds one more feature known as the behavioural intention. This theory predicts behavioural intention, which compromises pausing the attitude prediction and predicting the behaviour based on a situation. The concept of attitude and norms predicts behaviour changes, which helps the brands focus on the norms that trigger human emotions and sway one's attitude to leave a lasting effect in their minds.

\subsection{Role of Irritation Factor}

Advertisement triggers certain emotions in a person creating a lasting impact on the consumer. Previous purchase experience and the credibility of an ad develop a brand attitude that impacts consumers. These factors are antecedents to irritation due to advertisements (Chakrabarty \& Yelkur, 2005). Perception of the brand concerning their image generates Brand attitude based on them. It explains why the irritation factor does not have many hands in impacting the brands get attention (Munir et al., 2017). There is a need for contemporary research on the market before designing an advertisement. Consumers asked about the Irritation factor to different emotions like love, desire, longing, amusement, happiness, and warmth triggered by commercials. They help create a deep-rooted feeling 
and help the consumers understand the advertisement's motive (Mai \& Schoeller, 2009). To find out if Memorability in storytelling ads leads to purchase intention.

H1: The irritation factor in storytelling advertisements harms Purchase Intention.

\subsection{Role of Promotion via Word of Mouth}

Word of Mouth is one of the most influential promotions used for long-term product marketing or even nipping an advertisement if it does not go as planned. Several influencers recommend gaining the customer base, and their nod of approval takes any upcoming trade forward. As per Hennig et al. (2010), "Word-of-mouth is defined as any positive or negative statement made by customers experiences about a product or company, which is made available to a mass of people and institutions using the Internet." Based on the study by Ahmad et al. (2014), 20\% of WOM discussions relate to paid advertising, and such advertising-influenced conversations lead to customer recommendations of the particular brand. WOM affects the consumer decision-making process (Keller \& Fay, 2009), and consumer purchase decisions (Allsop et al., 2007). Hence, in this study, consumers have been asked questions on the WOM factor to determine if the WOM factor in storytelling ads leads to purchase intention.

H2: The WOM factor in storytelling advertisements significantly impacts Purchase Intention.

\subsection{Role of Entertainment Factor}

Entertainment is the gripping Factor that directly impacts the recall factor for the product (Osmonbekov \& Czaplewski, 2006). It is one of the most mainstream products of advertisements. It impacts consumer behavior and is based on recent research and data analysis. It became a rapidly evolving factor of this business that affects consumers' brand engagement (Hackley \& Tiwsakul, 2006). Entertainment has been proved to affect purchase intention in a positive way (Yang \& Smith, 2009). Few studies have shown that the entertainment factor helps gain consumer attention (Woltman Elpers et al., 2004) and creates a positive attitude for the brand (Mitchell \& Olson, 1981). Brand exposure increases due to the long-lasting impact of this Factor on the minds of the customer. Placement of the product and their sponsorship correctly analyze the market demand, and the entertainment factor influences these two in a promotion. Hence in this study, consumers have been asked questions on the entertainment factor to determine if the entertainment factor in storytelling ads leads to purchase intention.

H3: The entertainment factor in storytelling advertisements significantly impacts Purchase Intention.

\subsection{Role of Memorability}

Commercials trigger different emotions like love, desire, longing, amusement, 
happiness, and warmth. They help create a deep-rooted feeling and help the consumers understand the advertisement's motive (Mai \& Schoeller, 2009). This Factor defines the recall value and the importance of leaving a long-lasting memory amidst the consumers. Consumers tend initially to pay attention to an advertisement. However, the impactful Factor is the ad's end, affecting the Memorability (Wells et al., 2003). The remembrance and familiarity of a product's emotional synchronization with the situation are directly related to the purchasing and recall value. Advertisement is essential as this helps determine the consumer's behaviour and gauge the society's or an individual's attitude towards the product (Shokri, 2014). An advertisement's likeability affects the emotions and triggers their recognition of the outcome (Roozen, 2013). The brand attitude dependents also on the ad recall value (Galpin, 2012). Whenever a customer purchases a consequence, the recall of a brand for that product increases sales probability. Hence in this study consumers were asked questions with respect to "Memorability", in order to understand the impact of memorability factor on purchase intention.

H4: Memorability factor in Storytelling advertisements significantly impacts Purchase Intention

\subsection{Role of Informativeness}

Consumers want to get the full details within a limited time. Thus, it is essential to include complete information in the advertisement to get the best outcome. According to the study by Carlos et al. (2010), informational aspects in mobile advertising affect consumer attitude. As per (Siau \& Shen, 2003), information sent to customers primarily through mobile advertising should be accurate, timely, and valuable. As per (Milne \& Gordon, 1993), consumers prefer information that is relevant to them. The practical and hedonic aspects of the market create a significant difference in getting consumers' reactions. The more informative the advertisement, the better it reaches out to the masses. Consumers have been asked to determine if Informativeness in Storytelling ads leads to purchase intention.

H5: The informativeness factor in Storytelling advertisements significantly impacts Purchase Intention.

\subsection{Role of Time Duration}

Time is an essential factor when it is a matter of creating impact. The span of keeping the customers engaged must be short and crisp (Raj \& Roy, 2015). The entertainment factor needs to be top-notch, and the consumers need to, be engrossed while watching the advertisement, and thus the duration needs to be perfect. The time duration must not be too long or too little either. The right timing is essential, apart from delivering the content with a memorable impact and apt recall factors (Rao et al., 2015). Advertisement effectiveness is given proper attention to and considers the effectiveness of the advertisement. Thus, considering the time is crucial, there is a separate window when consumers 
gauge the advertising and recall it later. Certain aspects go hand in hand with this, like behavioural, psychological, selling, and communication (Larsen, 1987). Hence in this study, consumers have been asked the Time Duration factor to determine if time duration in storytelling ads leads to purchase intention.

H6: Time Duration factor in storytelling advertisements significantly impacts Purchase Intention.

Tsai (2020) found that video advertising stories impact customers' perception of the brand image, identity and promote the purchase intention of the brand. Ana (2020) wrote a comprehensive dissertation on the impact of Storytelling in the context of green fashion. However, some of its ideas are applicable for general business marketing. Our work focuses on analysing the underlying aspects of Storytelling in marketing terms and conducts an experiment based on this analysis. Figure 1 depicts the primary considerations influencing customers to decide if and what to buy.

\section{Research Methodology}

For this study, we use a mixed method of survey and sampling that has already been used in similar research (Lundqvist et al., 2013; Pan \& Chen, 2019; Hong et al., 2018). We presented Four storytelling advertisements to 150 volunteers who were asked to fill a questionnaire. The collected data were analysed using SPSS, Factor Analysis, and Variance Analysis.

A self-designed questionnaire was administered to the respondents. The questionnaire was developed on the basis of the 21 key identified attributes during the exploratory survey. For each attribute there was one question in the questionnaire and the respondents were asked to choose on a Likert scale between one to seven for every question (one being less important and seven being extremely important to them)

Scale Development and Reliability.

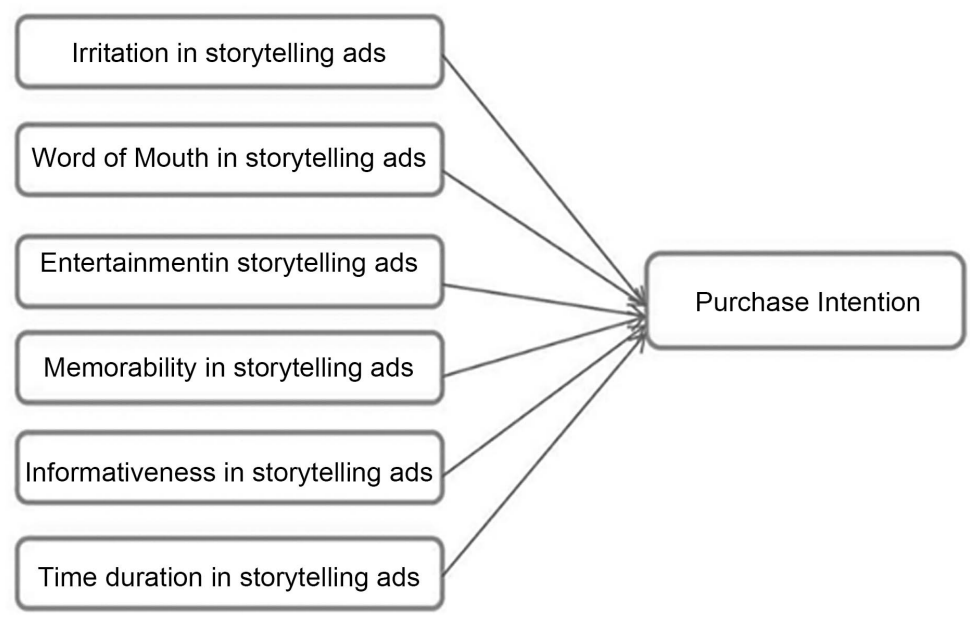

Figure 1. Conceptual model. 
We selected the Storytelling variables, Entertainment, Memorability, Informativeness, Duration, Word of mouth, and Irritation, considered independent variables, and Purchase intention considered a dependent variable. We measured these variables using a structured questionnaire with a five-point Likert scale. We used Cronbach alpha to ratify the scale reliability (Table 1), reaching the value of .86 above the acceptable value of .7; hence we can say that the scale is reliable.

We found that the data was suitable for our Factor Analysis.816 (see Table 2) is close to 1 and proves the data meets the standard required for the factor analysis.

\section{Sampling frame and Sampling method:}

We selected students and showed them several storytelling ads. Then, we asked them to fill a questionnaire. The best method of determining the sample size for Factor analysis is subject to item ratio (Costello \& Osborne, 2005). As per Costello and Osborne, "a large percentage of researchers report factor analysis using relatively small samples. In most of the studies in our survey (2.9 per cent) researchers performed analyses with subject to item ratio of 10:1 or less, which is an early and still prevalent rule of thumb many researchers use for determining a priori sample size. A surprisingly high proportion (almost one sixth) reported factor analyses based on subject to item ratios of 2:1 or less". Strict rules regarding sample size for exploratory factor analysis have mostly disappeared. Studies have revealed that adequate sample size is partly determined by the nature of the data (Fabrigar et al., 1999; MacCallum et al., 1999). In general, the stronger the data, the smaller the sample can be for an accurate analysis. "Strong Data" in factor analysis means uniformly high communalities without cross loadings, plus several variables loading strongly on each factor.

In the present study, data is collected from 150 respondents. At a subject size of 150 for 21 attributes under investigation, the subject to item ratio stands at $7: 1$. So this falls under $5: 1$ to $10: 1$ as per the above justification approximately 63.2 per cent of the factor analysis is done with this or lower subject to item ratio.

Table 1. Cronbach alpha test of reliability.

\begin{tabular}{cc}
\hline Cronbach's Alpha & N of Items \\
\hline .868 & 21 \\
\hline
\end{tabular}

Table 2. KMO and Bartlett's test.

\begin{tabular}{ccc}
\hline \multicolumn{3}{c}{ KMO and Bartlett's Test } \\
\hline Kaiser-Meyer-Olkin Measure of Sampling Adequacy & .816 \\
& Approx Chi-Square & 1662.653 \\
Bartlett's Test of Sphericity & $\mathrm{df}$ & 210 \\
& Sig. & .000 \\
\hline
\end{tabular}




\section{Analysis and Findings}

\subsection{Factor Analysis}

An exploratory Factor Analysis has been conducted and is based on the total Variance data. These six factors have been used to understand the impact on the consumer's purchase intention account for $72.25 \%$ (See Table 3) of the total Variance. The six factors identified Irritability (IR), Word of Mouth (WM), Entertainment (E), Memorability (M), Informativeness (IN), and Time consumption $(\mathrm{T})$.

Table 4 depicts the rotated component matrix which shows the 4 factors which have emerged after factor analysis and Table 3 depicts the Variance explained for the 4 factors which emerged after factor analysis. Component 1 stands for Irritability factor in the Storytelling advertisement and accounts for $16.5 \%$ of the total Variance; Component 2 stands for Word of Mouth (WOM), which accounts for $13.5 \%$ of the total Variance; Component 3 stands for Entertainment factor in the Storytelling advertisement and accounts for $13 \%$ of the total Variance; Component 4 stands for Memorability Factor in the Storytelling advertisement and accounts for $10.9 \%$ of the total Variance; Component 5 stands for Informativeness factor of watching a Storytelling advertisement and accounts for $10.7 \%$ of the total variance, and Component 6 stands for Time Consumption factor in the Storytelling advertisement and accounts for $7.5 \%$ of the total variance.

\subsection{Variance Analysis}

The Variance Analysis determines if two independent groups have significant differences or are related to each other. The analysed data has a significance level below .05. It proved that the considered values are associated with each other. We have taken a few factors and ran a test to draw a dependency on Purchase decisions.

Table 5 draws a connection between the impact of news spread via Word of Mouth on consumers' Purchase Intention by applying the Variance Analysis Test. The data is relevant and shows a significant influence on the purchase intention based on the data collected.

Table 3. Total variance explained.

\begin{tabular}{ccccccccccc}
\hline \multicolumn{10}{c}{ Total Variance Explained } \\
\hline Component & Total & \% of Variance & Cumulative \% & Total & \% of Variance & Cumulative \% & Total & \% of Variance Cumulative \% \\
\hline 1 & 7.500 & 35.713 & 35.713 & 7.500 & 35.713 & 35.713 & 3.465 & 16.500 & 16.500 \\
2 & 2.201 & 10.479 & 46.192 & 2.201 & 10.479 & 46.192 & 2.838 & 13.516 & 30.016 \\
3 & 1.910 & 9.095 & 55.287 & 1.910 & 9.095 & 55.287 & 2.733 & 13.013 & 43.029 \\
4 & 1.315 & 6.260 & 61.547 & 1.315 & 6.260 & 61.547 & 2.308 & 10.990 & 54.019 \\
5 & 1.209 & 5.759 & 67.306 & 1.209 & 5.759 & 67.306 & 2.257 & 10.750 & 64.769 \\
6 & 1.039 & 4.948 & 72.254 & 1.039 & 4.948 & 72.254 & 1.572 & 7.485 & 72.254 \\
\hline
\end{tabular}


Table 4. Rotated component matrix.

\begin{tabular}{|c|c|c|c|c|c|c|}
\hline \multicolumn{7}{|c|}{ Rotated Component Matrix } \\
\hline \multicolumn{7}{|c|}{ Component } \\
\hline & 1 & 2 & 3 & 4 & 5 & 6 \\
\hline IR 1 & .893 & & & & & \\
\hline IR & .875 & & & & & \\
\hline IR & .815 & & & & & \\
\hline IR & .812 & & & & & \\
\hline IR & .453 & & & & & \\
\hline WM & & .771 & & & & \\
\hline WM & & .763 & & & & \\
\hline WM & & .738 & & & & \\
\hline WM & & .730 & & & & \\
\hline E1 & & & .834 & & & \\
\hline $\mathrm{E} 2$ & & & .823 & & & \\
\hline E3 & & & .738 & & & \\
\hline $\mathrm{E} 4$ & & & .714 & & & \\
\hline M1 & & & & .786 & & \\
\hline M2 & & & & .772 & & \\
\hline M3 & & & & .754 & & \\
\hline IN1 & & & & & .818 & \\
\hline IN2 & & & & & .778 & \\
\hline $\mathrm{T} 1$ & & & & & .711 & \\
\hline \multirow[t]{2}{*}{$\mathrm{T} 2$} & & & & & & .884 \\
\hline & & & & & & .738 \\
\hline
\end{tabular}

Table 5. Variance analysis of word of mouth on purchase intention.

\begin{tabular}{lccccc}
\hline & Sum of Square & df & Mean Square & F & Sig \\
\hline Between Groups & 3.962 & 3 & 1.321 & 4.205 & .007 \\
\hline
\end{tabular}

Table 6 draws a connection between the Entertainment factor in the advertisement on consumers' Purchase Intention by applying the Variance Analysis Test. The data is relevant and shows a significant influence on the purchase intention based on data collected.

Table 7 shows that applying the Variance Analysis Test links the Memorability Factor's impact on consumers' Purchase Intention. The data is relevant and offers a significant influence on the purchase intention based on data collected.

Table 8 draws a connection between the impact Time duration of the advertisement on the Purchase Intention on consumers by applying the Variance Analysis Test. The data is relevant and shows a significant influence on the purchase intention based on data collected. 
Table 6. Variance analysis of entertainment on purchase intention.

\begin{tabular}{lccccc}
\hline & Sum of Square & df & Mean Square & F & Sig \\
\hline Between Groups & 10.121 & 3 & 3.374 & 8.323 & .000 \\
\hline
\end{tabular}

Table 7. Variance analysis of memorability on purchase intention.

\begin{tabular}{lccccc}
\hline & Sum of Square & df & Mean Square & F & Sig \\
\hline Between Groups & 2.277 & 3 & .759 & 3.542 & .016 \\
\hline
\end{tabular}

Table 8. Variance analysis of time duration on purchase intention.

\begin{tabular}{cccccc}
\hline & Sum of Square & df & Mean Square & F & Sig \\
\hline Between Groups & 12.168 & 3 & 4.056 & 4.063 & .008 \\
\hline
\end{tabular}

Thus, we can see that Word of Mouth, Entertainment, Memorability, and Time duration significantly impact Purchase intention.

\subsection{Hypotheses Testing Using Regression Analysis}

For regression analysis, Purchase Intention has been considered the dependent variable. The other factors, Irritation, Word-of-Mouth, Entertainment, Memorability, Informativeness, and Time consumption, are the independent variable compared to the purchase intention.

Table 9 is the summary of the coefficient, which shows that Factor 2 (WOM), Factor 3 (Entertainment), Factor 4 (Memorability), and Factor 6 (Time consumption) have significance values below .05, indicating $95 \%$ confidence in the value of the estimated coefficient. Factor 1 (Irritation) has a significance value of .5, proving the negative hypotheses. The p-value of Factor 5 (Informativeness) is .2, indicating that it is not significant. Table 9 depicts that Hypotheses 1, 2, 3, 4 , and 6 are accepted, rejecting the fifth hypothesis.

Using the analysis of variance and regression testing, we can accept the following hypotheses:

$\mathrm{H} 2$ : The WOM factor in storytelling advertisements significantly impacts Purchase Intention.

H3: Entertainment factor in storytelling advertisements significantly impacts Purchase Intention

H4: Memorability factor in storytelling advertisements significantly impacts Purchase Intention

H6: Time Duration factor in storytelling advertisements significantly impacts Purchase Intention.

However, based on the above analysis, the following two hypotheses stand rejected:

H1: The Irritation factor in storytelling advertisements harms Purchase Intention

H5: The informativeness factor in storytelling advertisements significantly impacts Purchase Intention. 
Table 9. Summary of the coefficient.

\begin{tabular}{|c|c|c|c|c|c|}
\hline \multicolumn{6}{|c|}{ Coefficients } \\
\hline \multirow[b]{2}{*}{ Model } & \multicolumn{2}{|c|}{$\begin{array}{l}\text { Unstandardized } \\
\text { Coefficients }\end{array}$} & \multirow{2}{*}{$\begin{array}{c}\text { Standardized } \\
\text { Coefficients } \\
\text { Beta }\end{array}$} & \multirow[b]{2}{*}{$\mathrm{t}$} & \multirow[b]{2}{*}{ Sig. } \\
\hline & B & Std Error & & & \\
\hline (Constant) & 3.612 & .059 & & 61.109 & \\
\hline REGR Factor Score 1 for analysis 1 & .034 & .059 & .046 & .575 & .566 \\
\hline REGR Factor Score 2 for analysis 1 & .139 & .059 & .185 & 2.336 & .021 \\
\hline REGR Factor Score 3 for analysis 1 & .182 & .059 & .243 & 3.061 & .003 \\
\hline REGR Factor Score 4 for analysis 1 & .123 & .059 & .165 & 2.078 & .04 \\
\hline REGR Factor Score 5 for analysis 1 & .064 & .059 & .085 & 1.075 & .284 \\
\hline REGR Factor Score 6 for analysis 1 & .145 & .059 & .195 & 2.453 & .015 \\
\hline
\end{tabular}

a Dependent Variable: AVG.

Table 10. Summary of hypotheses testing.

\begin{tabular}{|c|c|c|}
\hline Hypotheses & Significance Value & Result \\
\hline $\begin{array}{l}\text { H1: The irritation factor in storytelling advertisements } \\
\text { harms Purchase Intention. }\end{array}$ & .5 & Rejected \\
\hline $\begin{array}{l}\mathrm{H} 2 \text { : The WOM factor in storytelling advertisements } \\
\text { significantly impacts Purchase Intention. }\end{array}$ & .02 & Accepted \\
\hline $\begin{array}{l}\text { H3: The entertainment factor in storytelling } \\
\text { advertisements significantly impacts Purchase Intention. }\end{array}$ & .003 & Accepted \\
\hline $\begin{array}{l}\text { H4: Memorability factor in Storytelling advertisements } \\
\text { significantly impacts Purchase Intention }\end{array}$ & .04 & Accepted \\
\hline $\begin{array}{l}\text { H5: The informativeness factor in Storytelling } \\
\text { advertisements significantly impacts Purchase Intention. }\end{array}$ & .2 & Rejected \\
\hline $\begin{array}{l}\text { H6: Time Duration factor in storytelling advertisements } \\
\text { significantly impacts Purchase Intention. }\end{array}$ & .01 & Accepted \\
\hline
\end{tabular}

\section{Implication and Conclusion}

The study aimed to understand the importance of Storytelling for advertisement and identify the critical factors that impact their purchase intention. We used Twenty-one variables, clubbed them into six factors and their effect on the dependent variable. We observed that Word of mouth, Entertainment, Memorability, and Time duration factors impact Purchase-Intention. Still, the Irritation and Informativeness factors do not significantly affect the purchase intention of the consumer. Hence these variables must be considered while formulating storytelling ads to generate a better impact on consumers. Table 10 summarizes the hypotheses testing for the study. As we can observe from table 10, H2, H3, H4 and $\mathrm{H} 6$ are accepted and $\mathrm{H} 1$, and $\mathrm{H} 5$ are rejected. Thus WOM, Entertainment, Memorability and Time duration factor in storytelling ads exhibit significant 
impact on consumer purchase decision. (H2, H3, H4 and H6)

\section{Limitations of the Research}

The study was conducted to understand the importance of Storytelling in the field of advertisement and how it is gaining popularity in current times. The aim was to also understand the various factors that play a critical role in creating a memory for the consumers and having an impact on their purchase intention.

The study suffered from few limitations which can be overcome as part of future studies undertaken on the subject. The sample size was limited to 150 which may not be representative of the entire population hence future studies can be carried with larger sample size. Secondly the study used 4 storytelling advertisements which can be improved by undertaking more advertisements and probably different advertisements from different product genres which may give a different perspective to the topic of storytelling in advertisements.

\section{Conflicts of Interest}

The authors declare no conflicts of interest regarding the publication of this paper.

\section{References}

Ahmad, N., Vveinhardt, J., \& Ahmed, R. R. (2014). Impact of Word of Mouth on Consumer Buying Decision. European Journal of Business and Management, 6, 394-403.

Allsop, D. T., Bassett, B. R., \& Hoskins, J. A. (2007). Word-of-Mouth Research: Principles and Applications. Journal of Advertising Research, 47, 398-411. https://doi.org/10.2501/S0021849907070419

Ana, D. (2020). The Effect of Storytelling Advertising on Consumer Evaluation of Green Fashion in the Online Shopping Environment. MSc Dissertation, Universidade Católica Portuguesa.

Bhasin, H. (2018). What is Purchase Intention? Marketing91. https://www.marketing91.com/purchase-intention/

Carlos, F. B., Miguel, G B., \& Isabel, I. A. (2010). Entertainment and Informativeness as Precursory Factors of Successful Mobile Advertising Messages. Communications of the IBIMA, 2010, $11 \mathrm{p}$.

Chakrabarty, S., \& Yelkur, R. (2005). The Effects of Ad Irritation on Brand Attitudes. Journal of Promotion Management, 11, 37-48. https://doi.org/10.1300/J057v11n02 04

Cheung, G. W., \& Lau, R. S. (2012). A Direct Comparison Approach for Testing Measurement Invariance. Organizational Research Methods, 15, 167-198. https://doi.org/10.1177/1094428111421987

Costello, A. B., \& Osborne, J. W. (2005). Best Practices in Exploratory Factor Analysis: Four Recommendations for Getting the Most from Your Analysis. Practical Assessment, Research and Evaluation, 10, 1-9.

Decker, A. (2021). The Ultimate Guide to Storytelling. HubSpot. https://blog.hubspot.com/marketing/storytelling

Fabrigar, L. R., Wegener, D. T., MacCallum, R. C., \& Strahan, E. J. (1999). Evaluating the Use of Exploratory Factor Analysis in Psychological Research. Psychological Methods, 4, 272-299. https://doi.org/10.1037/1082-989X.4.3.272 
Galpin, J. (2012). The Overlooked Power of Media: Enhancing the Memorability of Communications. Millward Brown.

https://www.millwardbrown.ru/library/Millward Brown POV Medium Informs Mes sage 2012.pdf

Hackley, C., \& Tiwsakul, R. (2006). Entertainment Marketing and Experiential Consumption. Journal of Marketing Communications, 12, 63-75.

https://doi.org/10.1080/13527260500358608

Hennig, T., Malthouse, E. C., Friege, C., Gensler, S., Lobschat, L., Rangaswamy, A., \& Skiera, B. (2010). The Impact of New Media on Customer Relationships. Journal of Service Research, 13, 311-330. https://doi.org/10.1177/1094670510375460

Hong, S., Kang, J., \& Hubbard, G. T. (2018). The Effects of Founder's Storytelling Advertising. International Journal of Entrepreneurship, 22, 1-9.

Keller, E. D., \& Fay, B. (2009). The Role of Advertising in Word of Mouth. Journal of Advertising Research, 49, 154-158. https://doi.org/10.2501/S0021849909090205

Lars, P. (2012). Consumer Behavior: The Psychology of Marketing. Department of Marketing Marshall School of Business University of Southern California.

Larsen, R. J. (1987). Affect Intensity as an Individual Difference Characteristic: A Review. Journal of Research in Personality, 21, 1-39.

https://doi.org/10.1016/0092-6566(87)90023-7

Li., J., Zou, S. M., \& Yang, H. (2019) How Does “Storytelling” Influence Consumer Trust in We Media Advertorials? An Investigation in China. Journal of Global Marketing, 32, 319-334. https://doi.org/10.1080/08911762.2018.1562592

Lundqvist, A., Liljander, V., Gummerus, J., \& van Riel, A. C. (2013). The Impact of Storytelling on the Consumer Brand Experience: The Case of a Firm-Originated Story. Journal of Brand Management, 20, 283-297. https://doi.org/10.1057/bm.2012.15

MacCallum, R. C., Widaman, K. F., Zhang, S., \& Hong, S. (1999). Sample Size in Factor Analysis. Psychological Methods, 4, 84-99. https://doi.org/10.1037/1082-989X.4.1.84

Mai, L. W., \& Schoeller, G. (2009). Emotions, Attitudes, and Memorability Associated with TV Commercials. Journal of Targeting, Measurement and Analysis for Marketing, 17, 55-63. https://doi.org/10.1057/jt.2009.1

Milne, G. R., \& Gordon, M. E. (1993). Direct Mail Privacy-Efficiency Trade-Offs within an Implied Social Contract Framework. Journal of Public Policy \& Marketing, 12, 206-215. https://doi.org/10.1177/074391569101200206

Mitchell, A. A., \& Olson, J. C. (1981). Are Product Attribute Beliefs the Only Mediator of Advertising Effects on Brand Attitude? Journal of Marketing Research, 18, 318-332. https://doi.org/10.1177/002224378101800306

Munir, H., Rana, R. A., \& Bhatti, U. T. (2017). Factors Affecting Advertisement Avoidance through Mediating Role of Customer Perceived Value. International Journal of Research, 4, 961-975.

Osmonbekov, T. W., \& Czaplewski, A. J. (2006). eWOM: The Impact of Customer-toCustomer Online Know-How Exchange on Customer Value and Loyalty. Journal of Business Research, 59, 449-456. https://doi.org/10.1016/j.jbusres.2005.10.004

Pan, L., \& Chen, K. (2019). A Study on the Effect of Storytelling Marketing on Brand Image, Perceived Quality, and Purchase Intention in Ecotourism. Ekoloji, 28, 705-712.

Raj, M. P. M., \& Roy, S. (2015). Impact of Brand Image on Consumer Decision-making: A Study on High-technology Products. Global Business Review, 16, 463-477. https://doi.org/10.1177/0972150915569934

Rao, W., Zhao, K., Zhang, Y., Hui, P., \& Tarkoma, S. (2015). Towards Maximizing Timely 
Content Delivery in Delay Tolerant Networks. IEEE Transactions on Mobile Computing, 14, 755-769. https://doi.org/10.1109/TMC.2014.2330296

Roozen, I. (2013). The Impact of Emotional Appeal and the Media Context on the Effectiveness of Commercials for Not-for-Profit and For-Profit Brands. Journal of Marketing Communications, 19, 198-214. https://doi.org/10.1080/13527266.2011.619555

Shah, H., Aziz, A., Jaffari, A. R., Waris, S., Ejaz, W., Fatima, M., \& Sherazi, K. (2012). The Impact of Brands on Consumer Purchase Intentions. Asian Journal of Business Management, 4, 105-110.

Shokri, S. (2014). Role of Psychological Factors on Advertising Effectiveness. International Journal of Academic Research in Business and Social Sciences, 4, 2222-6990.

Siau, K., \& Shen, Z. X. (2003). Mobile Communications and Mobile Services. International Journal of Mobile Communications, 1, 3-14. https://doi.org/10.1504/IJMC.2003.002457

Tsai, M. C. (2020). Storytelling Advertising Investment Profits in Marketing: From the Perspective of Consumers' Purchase Intention. Mathematics, 8, Article No. 1704. https://doi.org/10.3390/math8101704

Wells, W. D., Burnett, J., \& Moriarty, S. (2003) Advertising Principles \& Practice (6th ed.). Pearson Education.

Woltman Elpers, J. L. C. M., Mukherjee, A., \& Hoyer, W. D. (2004). Humor in Television Advertising: A Moment-to-Moment Analysis. Journal of Consumer Research, 31, 592598. https://doi.org/10.1086/425094

Yang, X. J., \& Smith, R. E. (2009). Beyond Attention Effects: Modeling the Persuasive and Emotional Effects of Advertising Creativity. Marketing Science, 28, 935-949. https://doi.org/10.1287/mksc. 1080.0460

Yang, Y. K. (2018). A Study on the Correlations among Tourism Storytelling, Perception of Touristic Attractiveness, and Behavioral Intention for Baekje Historic Areas. International Journal of Pure and Applied Mathematics, 118, 1-15.

Yueh, H. P., \& Zheng, Y. L. (2019). Effectiveness of Storytelling in Agricultural Marketing: Scale Development and Model Evaluation. Frontiers in Psychology, 10, Article No. 452. https://doi.org/10.3389/fpsyg.2019.00452 